\title{
The Effects of Whole-Body Vibration on Fatigue in Vertical Jump Performance and Isometric Mid-Thigh Pull Measures
}

\author{
Nicole C. Dabbs ${ }^{1, *}$, Sergio Espericueta ${ }^{1}$, Sean Bonilla ${ }^{1}$ and Margaret T. Jones ${ }^{2} \mathbb{C}$ \\ 1 Department of Kinesiology, California State University, San Bernardino, CA 92407, USA; \\ 006194782@coyote.csusb.edu (S.E.); $005843249 @$ coyote.csusb.edu (S.B.) \\ 2 School of Sport Recreation and Tourism Management, George Mason University, Fairfax, VA 22030, USA; \\ mjones15@gmu.edu \\ * Correspondence: ndabbs@csusb.edu; Tel.: +1-909-537-7565
}

Citation: Dabbs, N.C.; Espericueta, S.; Bonilla, S.; Jones, M.T. The Effects of Whole-Body Vibration on Fatigue in Vertical Jump Performance and Isometric Mid-Thigh Pull Measures. Vibration 2021, 4, 759-767. https:// doi.org/10.3390/vibration4040042

Academic Editor: Setsuo Maeda

Received: 31 July 2021

Accepted: 23 September 2021

Published: 25 September 2021

Publisher's Note: MDPI stays neutral with regard to jurisdictional claims in published maps and institutional affiliations.

Copyright: (C) 2021 by the authors. Licensee MDPI, Basel, Switzerland. This article is an open access article distributed under the terms and conditions of the Creative Commons Attribution (CC BY) license (https:/ / creativecommons.org/licenses/by/ $4.0 /)$.

\begin{abstract}
The purpose of this study is to determine the effects of coupling WBV and acute muscular fatigue to determine its effects on countermovement vertical jump (CMVJ) performance and isometric mid-thigh pull (IMTP). Twenty-eight healthy active adults volunteered for five-day study. Testing sessions 2-5 included one of four conditions: No WBV and no fatigue (CON), WBV and fatigue $(\mathrm{WBV}+\mathrm{FAT}), \mathrm{WBV}$ and no fatigue (WBV), and no WBV and fatigue (FAT). WBV was performed using a frequency of $50 \mathrm{~Hz}$ and a low amplitude while performing quarter squats for a total of $4 \mathrm{~min}$ with a $30 \mathrm{~s}$ rest or work ratio. Lower-body fatigue induced using Bosco fatigue protocol. CMVJ and IMTP were performed on force plates. SPSS was used to perform a $2 \times 2$ Repeated Measures ANOVA. Significant main effects were found for fatigue in CMVJ-height and CMVJ-peak ground reaction force, no significant main effect for WBV, and no significant interactions. Lower-body fatigue decreases vertical jump performance, and WBV did not attenuate the detrimental effects of lower-body fatigue.
\end{abstract}

Keywords: force; muscle fatigue; vibration; peak velocity

\section{Introduction}

Activities that involve a high physical demand such as weightlifting or high-intensity interval training require muscular strength and power [1-3]. Participation in such activities may cause acute muscular fatigue, which is a decrease in the force producing capability of muscle [2,4]. It is well established that acute muscular fatigue leads to a decrease in force production [5,6] and explosive power [5]. The amount of muscular fatigue varies by the duration, intensity, and type of activity $[7,8]$. In order for active individuals to perform optimally, the muscles they are using should not be fatigued; therefore, determining strategies to assist in recovery from fatigue or to reduce fatiguing effects is of interest. It is recommended to couple high physical demanding activities with appropriate rest intervals [4], thereby enabling the fatigued muscle to recover. Internal modalities such as stretching, warm-ups, and low-intensity exercise may be useful before or after fatiguing activities to assist in recovery $[9,10]$. Several external modalities have been shown to assist with recovery following exercise induced muscle damage [11-13], yet their effect on acute muscular fatigue has not been investigated.

An external modality that has been shown to increase performance measures is wholebody vibration (WBV), which conveys oscillating vibrations to the body via prescribed frequency and amplitude settings. The variety of frequencies, amplitudes, and type of WBV platforms (vertical, tri-planar, pivotal) has been shown to have varying effects on muscle performance [14-18]. The inconsistencies in these variables have contributed to varying outcomes in performance measures. However, WBV has been shown to increase countermovement vertical jump (CMVJ) performance [19-23], strength [20,24,25], and power output $[19,21,23,24,26]$. Research demonstrating positive effects of utilizing WBV concluded that it may be useful to assist in improving a variety of performance measures. 
WBV is thought to cause the muscle-tendon complex to have quick and small changes in length, often referred to as the tonic vibration reflex [22,27]. The mechanism of WBV is not completely understood, but it is speculated that the tonic vibration reflex induces Ia muscle spindle afferents and suppresses the H-reflex $[15,28]$, allowing more force to be produced. Force production is a key variable that contributes to performance; therefore, individuals commonly seek training programs and external modalities to maximize force production.

Maximizing force production and the ability to generate that force with a high velocity is critical to reaching a high level of performance [29]. Training programs that aim to increase peak force and peak power output in order to contribute to an increased performance outcomes in powerlifting, weightlifting, sprinting, and jumping are well-established in the literature [30,31] For example, the performance measures of isometric mid-thigh pull (IMTP) are correlated with a variety of dynamic performance movements [32-35]. Therefore, utilizing IMTP may be useful to assess force production. More recently, investigators have examined how WBV affects IMTP performance [36-38]. Results are mixed in that there was no change in force production with the influence of WBV $[36,37]$ while another study reported positive effects at $15 \mathrm{~min}$ post WBV exposure [38].

Explosive peak power is often assessed with CMVJ [1,2,4,39-41]. Although it is wellestablished that CMVJ performance is hindered following acute muscular fatigue, it is unclear how CMVJ performance would be affected with the implementation of WBV prior to a fatiguing activity. WBV could serve to decrease the detrimental effects of muscular fatigue; however, this is only speculation. Due to the growing body of evidence, it is well documented that WBV has been shown to increase performance measures, specifically vertical jump performance. It has also been well supported that following an acute bout of muscular fatigue, vertical jump performance decreases [5]. The effect of acute fatigue and WBV on IMTP force production has not been clearly established. Therefore, the aim of the current study was to determine the effect of an acute bout of WBV on muscular fatigue as assessed by CMVJ and IMTP performance. It was hypothesized that WBV exposure prior to fatigue would attenuate fatigue and improve performance. This is an under-researched area, and no previous literature has examined if WBV could attenuate the detrimental effects of acute lower-body fatigue, potentially resulting in an increase in performance.

\section{Materials and Methods}

A four-period cross-over design was used to determine the effects WBV and fatigue on lower-body performance. Twenty-eight recreationally trained men and women (mean \pm SD, age range 20-28 years; height $172.78 \pm 11.41 \mathrm{~cm}$; body mass $79.27 \pm 16.68 \mathrm{~kg}$ ), who had been active 3-5 days per week for 6 months immediately prior to the study, volunteered to participate in one familiarization day and four testing days. Participants had to meet inclusion criteria of no musculoskeletal injuries in the last 6 months and have been active for at least 6 months prior to participation. Participants read and signed an Institutional Review Board (IRB) approved written informed consent document, followed by completion of the Physical Activity Readiness Questionnaire and health history questionnaire. The study was approved by the IRB at California State University, San Bernardino (\# IRBFY2019-119). At least $24 \mathrm{~h}$ prior to the first testing day, participants were familiarized with testing procedures, and barefoot height, body mass, and mid-thigh measurement were recorded. All testing days were separated by at least $24 \mathrm{~h}$ with no more than 1 week between sessions and participants were asked to refrain from exercise activities $24 \mathrm{~h}$ prior to testing days. During each testing day, a $24 \mathrm{~h}$ history questionnaire was used to assess if participants complied with no exercise $24 \mathrm{~h}$ prior to testing, took any medications, and slept 6-8 h.

\subsection{Procedures}

During the next four visits to the lab, all testing procedures were the same. During each day of testing, one of four conditions were randomly assigned to participants. The four conditions were: no WBV and no fatigue (CON), WBV following fatigue (WBV + FAT), 
WBV following no fatigue (WBV), and no WBV following fatigue (FAT). Participants performed a five-minute dynamic warm-up that included: 2 sets of $15 \mathrm{~m}$ of jogs, high knees, exaggerated lunges, walking planks, and leg swings for $30 \mathrm{~s}$. Following warm-up, participants completed one of the four conditions prior to testing.

During conditions with WBV, participants stood on an AIRdaptive Power Plate system (Power Plate North America, Northbrook, IL, USA) and performed continuous quarter squats for $30 \mathrm{~s}$ while standing on a one-inch cushion pad. Participants were instructed to wear the same shoes for all sessions and to not hold on to the handlebars for support. The WBV protocol was set at a frequency of $50 \mathrm{~Hz}$ with a low amplitude $(2-4 \mathrm{~mm})$ and participants had a 1:1 work to rest ratio four times ( $30 \mathrm{~s}$ on, $30 \mathrm{~s}$ off $\times 4$ ). This protocol was administered based off previous research [11,19]; however, the researchers increased the frequency from $30 \mathrm{~Hz}$ to $50 \mathrm{~Hz}$ in order to increase the intensity. During rest participants stepped down from the platform and stood on the ground. In conditions where no WBV was administered, participants stood on the platform and performed the 1:1 work to rest ratio of quarter squats four times with the platform in the off position. During conditions with the fatiguing protocol, participants performed the Bosco fatigue protocol [42] which consisted of body weight squat jumps at 90 degrees knee angle for $60 \mathrm{~s}$ continuously. To ensure participants completed the required squat depth, an elastic band was stretched between two chairs as a marker. The height of the elastic band was adjusted to the height of each participant, where they were instructed to touch the band with their glutes for each jump squat. During conditions where there was no fatigue, participants stood and waited $60 \mathrm{~s}$ before assessments, to time match other conditions.

Participants then performed three trials of IMTP with $5 \mathrm{~s}$ rest between each trial. During the IMTP, participants pulled against a fixed barbell that was adjusted to be at the middle of their thigh and were instructed to pull as hard as possible for $3 \mathrm{~s}$. The IMTP was performed on a portable AMTI AccuPower-Optimized force plate (Advanced Mechanical Technology, Inc., Watertown, USA, model: ACP-O) to assess IMTP peak ground reaction forces (IMTP-pGRF). Accupower 2.0 software was used to calculate pGRF and the highest of the three trials used for analysis. Following IMTPs, participants performed three CMVJ with $15 \mathrm{~s}$ rest between each jump using an inground AMTI force plate (Advanced Mechanical Technology, Inc., Watertown, MA, USA, model: BP 6009001000) and Vertec ${ }^{\circledR}$ jump tester simultaneously. During the CMVJ, participants were instructed to stand with their feet apart, bend at the knees quickly and jump explosively as high as possible with the arm swing. A customized LabVIEW software (version 1.0, National Instruments Corporation, Austin, TX, USA) was used to calculate the following dependent variables from the force plate data: CMVJ peak ground reaction force (CMVJpGRF), peak power (CMVJ-PP), and peak velocity (CMVJ-PV) and the highest of the three jumps were used for analysis. Participant's CMVJ height (CMVJ-H) was recorded by measuring the difference between the fully extended standing reach height and the maximal vertical jump-and reach height, the highest CMVJ-H was used for analysis. See Figure 1 for testing protocol timeline.

\subsection{Statistical Analysis}

Statistical analysis was performed with SPSS software (IBM SPSS 27). A $2 \times 2$ repeated measures analysis of variance (RMANOVA) was conducted to determine differences between four conditions for all jumping (CMVJ-H, CMVJ-pGRF, CMVJ-PP, CMVJ-PV) and IMTP (IMTP-pGRF) measures. An alpha level was set a priori at 0.05 to determine significant main effects between conditions. 


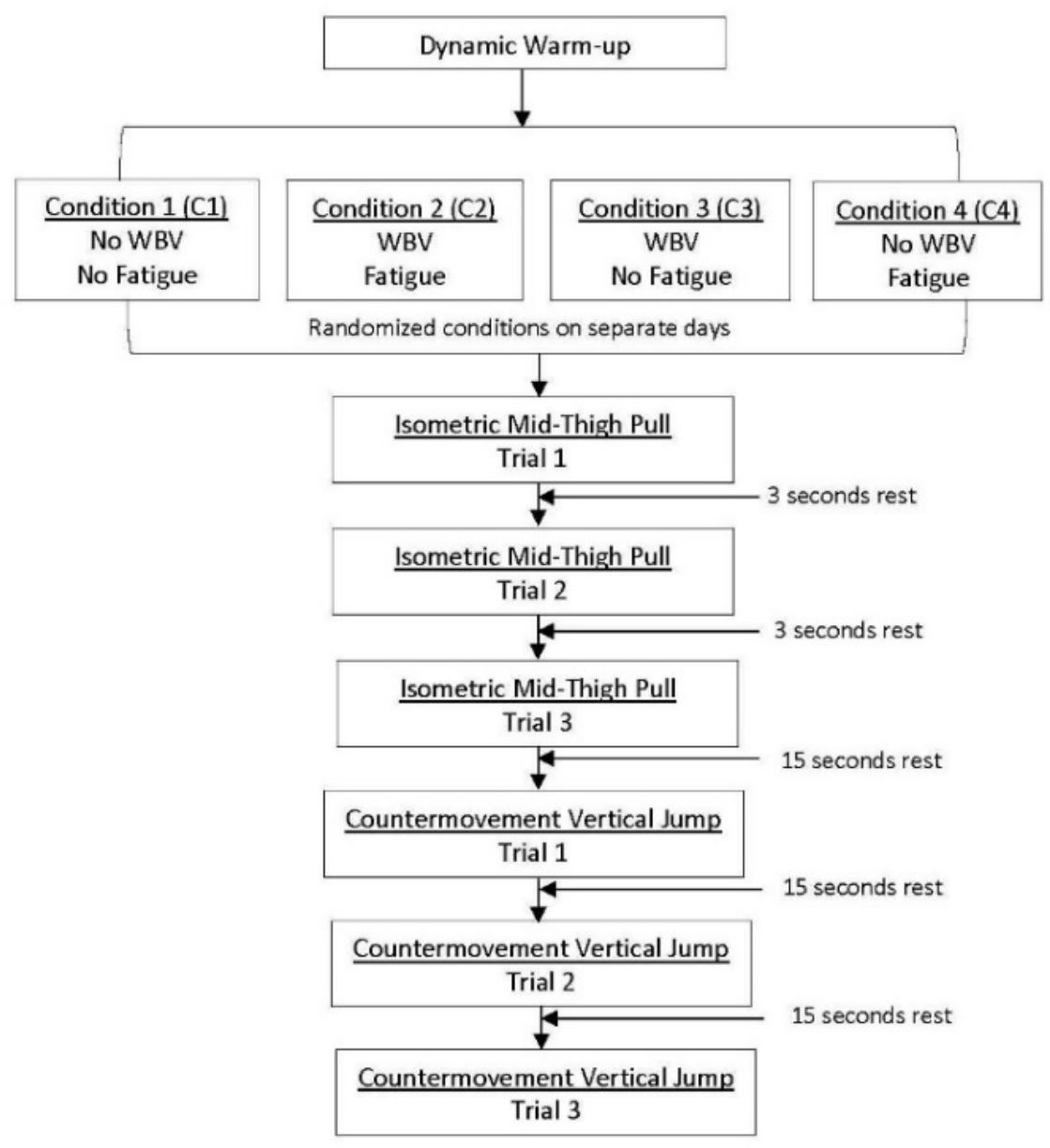

Figure 1. Testing protocol.

\section{Results}

Significant main effects were found for fatigue only in CMVJ-H and CMVJ-PF. There were no significant main effects for WBV or significant interactions between fatigue and WBV. Means and standard deviations of all variables both absolute and relative can be found in Table 1. The main effects for fatigue and WBV and interactions $p$-values, effect size and F-test provided in Table 2. Individual differences were not statically analyzed, however it may be beneficial to visualize the comparison between WBV + FAT and FAT for each participant, as shown in Figure 2.

Table 1. Vertical jump and isometric mid-thigh pull mean and SD data $(\mathrm{n}=28)$.

\begin{tabular}{|c|c|c|c|c|}
\hline & WBV + FAT & WBV & FAT & $\mathrm{CON}$ \\
\hline \multicolumn{5}{|c|}{ Countermovement Vertical Jump } \\
\hline Height (cm) & $49.16 \pm 13.51$ & $54.83 \pm 14.68$ & $48.84 \pm 14.41$ & $54.25 \pm 13.17$ \\
\hline pGRF (N) & $1796.46 \pm 498.62$ & $1841.75 \pm 531.81$ & $1792.42 \pm 470.61$ & $1893.81 \pm 530.85$ \\
\hline pGRF/BM (N/kg $\left.{ }^{-1}\right)$ & $22.13 \pm 5.34$ & $23.61 \pm 3.49$ & $22.92 \pm 2.82$ & $23.33 \pm 5.86$ \\
\hline $\mathrm{PP}(\mathrm{W})$ & $4219.03 \pm 1830.28$ & $4363.07 \pm 1641.37$ & $3992.95 \pm 1408.50$ & $4314.74 \pm 1520.11$ \\
\hline $\mathrm{PP} / \mathrm{BM}\left(\mathrm{W} / \mathrm{kg}^{-1}\right)$ & $51.61 \pm 22.16$ & $54.31 \pm 13.34$ & $49.88 \pm 11.45$ & $51.68 \pm 15.60$ \\
\hline $\mathrm{PV}(\mathrm{m} / \mathrm{s})$ & $2.65 \pm 0.40$ & $2.81 \pm 0.42$ & $2.64 \pm 0.37$ & $2.81 \pm 0.40$ \\
\hline $\mathrm{PV} / \mathrm{BM}\left(\mathrm{m} / \mathrm{s} / \mathrm{kg}^{-1}\right)$ & $0.04 \pm 0.02$ & $0.04 \pm 0.01$ & $0.03 \pm 0.01$ & $0.04 \pm 0.01$ \\
\hline \multicolumn{5}{|c|}{ Isometric Mid-Thigh Pull } \\
\hline pGRF (N) & $2125.62 \pm 602.06$ & $2019.06 \pm 688.32$ & $2123.92 \pm 572.84$ & $2140.19 \pm 575.87$ \\
\hline pGRF / BM (N/kg $\left.{ }^{-1}\right)$ & $26.70 \pm 4.70$ & $25.60 \pm 6.92$ & $26.80 \pm 4.83$ & $26.95 \pm 4.54$ \\
\hline
\end{tabular}

Peak ground reaction force (pGRF); peak power (PP); peak velocity (PV); whole-body vibration = WBV; $\mathrm{CON}=$ no WBV and no fatigue; $\mathrm{WBV}+\mathrm{FAT}=\mathrm{WBV}$ and fatigue; $\mathrm{WBV}=\mathrm{WBV}$ and no fatigue; $F A T=$ No $\mathrm{WBV}$ and fatigue. 
Table 2. Vertical jump and isometric mid-thigh pull main effects and interaction results $(n=28)$.

\begin{tabular}{|c|c|c|c|}
\hline & WBV & FAT & $\mathbf{W B V} \times \mathbf{F A T}$ \\
\hline \multicolumn{4}{|c|}{ Countermovement Vertical Jump } \\
\hline Height $(\mathrm{cm})$ & $p=0.63 ; \mathrm{F}=0.23 ; \eta_{\mathrm{p}}^{2}=0.01$ & ${ }^{*} p<0.01 ; \mathrm{F}=30.09 ; \eta_{\mathrm{p}}{ }^{2}=0.52$ & $p=0.89 ; \mathrm{F}=0.02 ; \eta_{\mathrm{p}}^{2}=0.001$ \\
\hline pGRF (N) & $p=0.42 ; \mathrm{F}=0.67 ; \eta_{\mathrm{p}}^{2}=0.03$ & ${ }^{*} p=0.04 ; \mathrm{F}=4.85 ; \eta_{\mathrm{p}}{ }^{2}=0.16$ & $p=0.29 ; \mathrm{F}=1.17 ; \eta_{\mathrm{p}}^{2}=0.05$ \\
\hline $\mathrm{pGRF} / \mathrm{BM}\left(\mathrm{N} / \mathrm{kg}^{-1}\right)$ & $p=0.71 ; \mathrm{F}=0.14 ; \eta_{\mathrm{p}}{ }^{2}=0.01$ & $p=0.22 ; \mathrm{F}=1.60 ; \eta_{\mathrm{p}}^{2}=0.06$ & $p=0.45 ; \mathrm{F}=0.59 ; \eta_{\mathrm{p}}{ }^{2}=0.02$ \\
\hline $\mathrm{PP}(\mathrm{W})$ & $p=0.30 ; \mathrm{F}=1.14 ; \eta_{\mathrm{p}}{ }^{2}=0.04$ & $p=0.11 ; \mathrm{F}=2.74 ; \eta_{\mathrm{p}}^{2}=0.10$ & $p=0.52 ; \mathrm{F}=0.42 ; \eta_{\mathrm{p}}{ }^{2}=0.02$ \\
\hline $\mathrm{PP} / \mathrm{BM}\left(\mathrm{W} / \mathrm{kg}^{-1}\right)$ & $p=0.28 ; \mathrm{F}=1.23 ; \eta_{\mathrm{p}}^{2}=0.04$ & $p=0.28 ; \mathrm{F}=1.19 ; \eta_{\mathrm{p}}^{2}=0.04$ & $p=0.84 ; \mathrm{F}=0.04 ; \eta_{\mathrm{p}}^{2}=0.002$ \\
\hline $\mathrm{PV}(\mathrm{m} / \mathrm{s})$ & $p=0.32 ; \mathrm{F}=1.02 ; \eta_{\mathrm{p}}^{2}=0.04$ & $p=0.54 ; \mathrm{F}=0.39 ; \eta_{\mathrm{p}}^{2}=0.02$ & $p=0.32 ; \mathrm{F}=1.02 ; \eta_{\mathrm{p}}{ }^{2}=0.04$ \\
\hline $\mathrm{PV} / \mathrm{BM}\left(\mathrm{m} / \mathrm{s} / \mathrm{kg}^{-1}\right)$ & $\begin{array}{r}p=0.29 ; \mathrm{F}=1.17 ; \eta_{\mathrm{p}}{ }^{2}=0.04 \\
\text { Isometric } \mathrm{I}\end{array}$ & $\begin{array}{l}p=0.74 ; \mathrm{F}=0.11 ; \eta_{\mathrm{p}}{ }^{2}=0.004 \\
\text {-Thigh Pull }\end{array}$ & $p=0.79 ; \mathrm{F}=0.07 ; \eta_{\mathrm{p}}{ }^{2}=0.07$ \\
\hline pGRF (N) & $p=0.21 ; \mathrm{F}=1.66 ; \eta_{\mathrm{p}}^{2}=0.06$ & $p=0.35 ; \mathrm{F}=0.91 ; \eta_{\mathrm{p}}^{2}=0.03$ & $p=0.20 ; \mathrm{F}=1.70 ; \eta_{\mathrm{p}}^{2}=0.06$ \\
\hline $\mathrm{pGRF} / \mathrm{BM}\left(\mathrm{N} / \mathrm{kg}^{-1}\right)$ & $p=0.17 ; \mathrm{F}=1.97 ; \eta_{\mathrm{p}}{ }^{2}=0.07$ & $p=0.37 ; \mathrm{F}=0.82 ; \eta_{\mathrm{p}}{ }^{2}=0.03$ & $p=0.24 ; \mathrm{F}=1.42 ; \eta_{\mathrm{p}}{ }^{2}=0.05$ \\
\hline
\end{tabular}

Peak ground reaction force (pGRF); peak power (PP); peak velocity $(\mathrm{PV})$; whole-body vibration $=\mathrm{WBV}$; FAT = fatigue; ${ }^{*}$ indicates significant $(p<0.05)$ main effect.

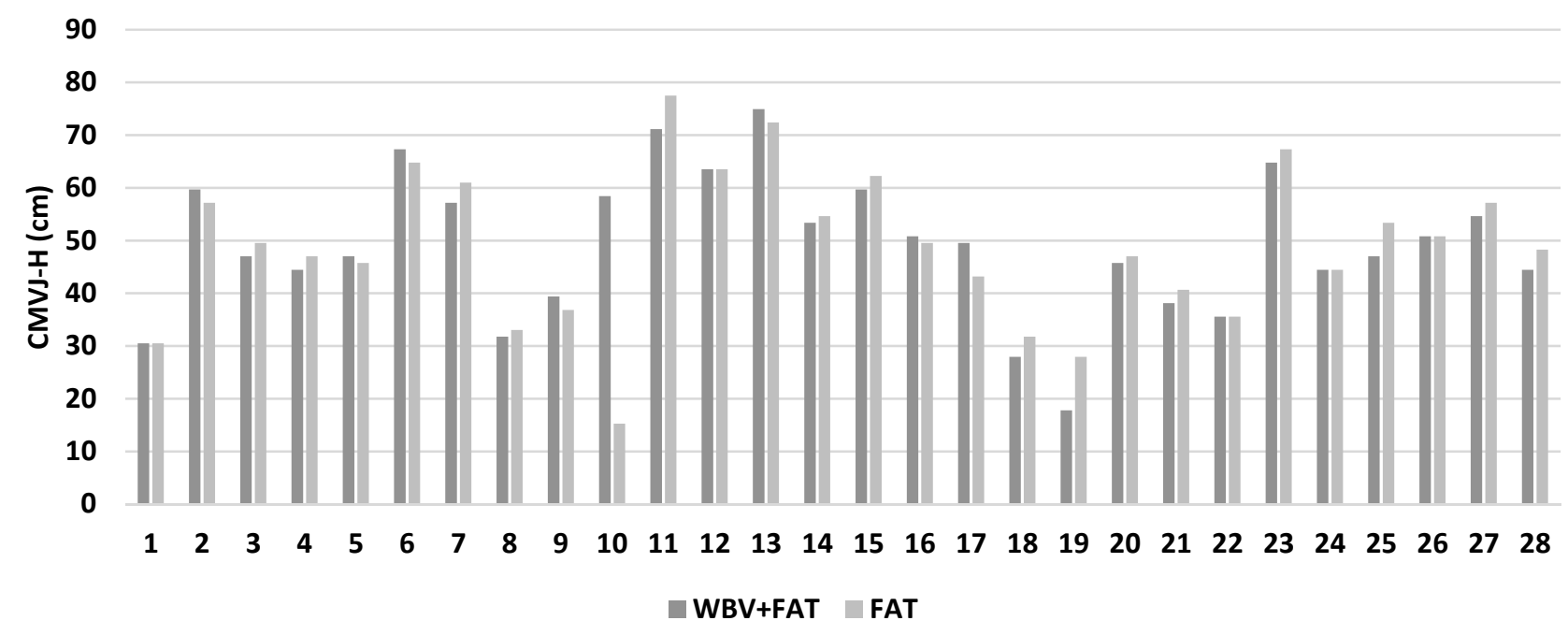

Figure 2. Individual countermovement vertical jump height (CMVJ-H) comparing conditions WBV + FAT and FAT.

\section{Discussion}

The aim of the current study was to determine the effect of an acute bout of WBV on muscular fatigue as assessed by countermovement vertical jump and isometric midthigh pull performance. The main findings were that WBV did not attenuate fatigue when measuring force, power, height, and velocity of CMVJs. However, differences in performance were found in conditions when fatigue was present. There were no significant interactions in CMVJ performance between WBV and fatigue, indicating WBV did not attenuate fatigue and improve performance. Additionally, were no main effects for WBV, thereby demonstrating WBV did not affect performance. Furthermore, there were no significant main effects or interactions in pGRF for IMTP. Therefore, the researchers reject their research hypothesis that stated, when individuals are exposed to WBV prior to fatigue, it will attenuate fatigue and improve performance compared to no influence of WBV.

The Bosco fatigue protocol was effective in fatiguing the lower-body during a CMVJ, which is consistent with previous literature [5]. In a recent study, Cooper et al., found that both CMVJ and static jumps decreased power and height of jumps following implementation of the Bosco fatigue protocol, which is consistent with the current study [5]. Other research supports a decrease in jumping performance following a fatiguing activity such as running or heavy lifting [43-45]. Certain research findings indicate that a WBV protocol may elicit fatigue $[20,46,47]$, which may contribute to our findings. However, there were no interactions between WBV and fatigue, indicating that it is unlikely WBV fatigued participants more than the Bosco fatigue protocol. Due to the lack of main effect for fatigue, 
it is unclear if the fatigue protocol effected IMTP, this may be due to the specificity of the type of fatigue protocol used. The fatigue protocol implemented in the current study $(60 \mathrm{~s}$ of continuous jump squats) mimics jumping explosiveness but does not mimic the specific isometric muscle actions in IMTPs. Therefore, it is likely that the fatigue protocol was not specific enough to elicit fatigue on the IMTP. No research related to fatigue and IMTP was located, thereby preventing comparison of current findings to previous data.

Interestingly, the current study did not improve CMVJ performance in the condition where WBV was present compared to the control condition. There is conflicting literature in this area, and it is speculated that it is due to the inconsistencies in WBV platforms, frequency, amplitude, exposure time, and rest times across studies. The current study used a triplanar platform, $50 \mathrm{~Hz}$ frequency, low amplitude, and a 1:1 work to rest ratio of $30 \mathrm{~s}$ for $4 \mathrm{~min}$. Our results are in support of others that reported no effect of WBV when assessing CMVJ [22,48]. Bullock et al., used a WBV protocol of $30 \mathrm{~Hz}$ with a $4 \mathrm{~mm}$ amplitude and an exposure of $3 \times 60 \mathrm{~s}$ of a 1:3 work to rest ratio and rested $5 \mathrm{~min}$ before testing [48]. There were differences in WBV protocols between the current study and Bullock et al., study, which makes it difficult to compare but both resulted in no differences in CMVJ performance variables. In contrast, there have been several studies that have shown a positive influence of WBV on CMVJ performance $[19,22,23,49,50]$. Although there were no positive effects of WBV in the current study, there were also no detrimental effects of WBV, indicating WBV exposure did not negatively affect CMVJ performance.

More recently, IMTP has been researched as a means to measure lower-body performance and has been correlated with other performance measures. The few studies that have investigated the effects of WBV on IMTP [36-38] show conflicting results. The current study found no effect of WBV on IMTP peak force, which is similar to two other studies $[36,37]$. The current study had similar WBV settings, the only difference was Cazás-Moreno et al., used $30 \mathrm{~Hz}$ frequency when the current study used $50 \mathrm{~Hz}$ [36], whereas Hornsby et al., used $30 \mathrm{~Hz}$ frequency with one $30 \mathrm{~s}$ bout of WBV [37]. Conversely, positive effects have been reported for WBV prior to IMTPs with a rest interval of $15 \mathrm{~min}$ after WBV exposure [38]. A difference in results compared to the current study may be a result of the time between WBV exposure and testing, the current study tested IMTP peak force immediately after WBV. Rest intervals after exposure should be considered when comparing research results because it may have substantial effects on outcomes.

The current study is not without limitations. A more homogeneous participation group may have been advantageous instead of a convenient active sample to contribute to more consistencies in external factors. The frequency of $50 \mathrm{~Hz}$ may have been too high of a frequency for participants and a lower frequency would decrease the intensity and possibly change performance outcomes. Although familiarized with IMTP prior to the current study, most participants were new to performing this isometric muscle action. The inclusion of more familiarization days may be beneficial. Future directions from this study may be testing similar parameters on a sport specific population and changing WBV variables such as rest time and frequency.

\section{Conclusions}

This study aimed to investigate a unique question to determine if incorporating WBV prior to a fatiguing exercise protocol would attenuate the effects of fatigue and change CMVJ and IMTP performance outcomes. Although our study did not produce results we hypothesized, it adds to the literature of external modalities used for preparing the muscle to fatigue. This study did demonstrate that lower-body fatigue resulted in a decrease in CMVJ performance due to the reduction in force generating capabilities when a muscle is fatigued.

Author Contributions: Conceptualization, N.C.D.; methodology, N.C.D., S.E., M.T.J. and S.B.; software, N.C.D., S.E. and S.B.; formal analysis, N.C.D. and M.T.J.; investigation, N.C.D., S.E. and S.B.; resources, N.C.D., S.E. and S.B.; data curation, N.C.D. and S.E.; writing-original draft preparation, 
N.C.D. and M.T.J.; writing-review and editing, N.C.D., M.T.J., S.E. and S.B.; supervision, N.C.D.; All authors have read and agreed to the published version of the manuscript.

Funding: This research received no external funding.

Institutional Review Board Statement: The study was conducted according to the guidelines of the Declaration of Helsinki, and approved by the Institutional Review Board at California State University, San Bernardino, 92407, approval date: 23 January 2020.

Informed Consent Statement: Informed consent was obtained from all subjects involved in the study.

Data Availability Statement: Data is stored with the primary investigator and corresponding author.

Conflicts of Interest: The authors declare no conflict of interest.

\section{References}

1. Loturco, I.; Pereira, L.; Cal Abad, C.; D'Angelo, R.; Fernandes, V.; Kitamura, K.; Kobal, R.; Nakamura, F. Vertical and Horizontal Jump Tests Are Strongly Associated with Competitive Performance in 100-M Dash Events. J. Strength Cond. Res. 2015, 29, 19661971. [CrossRef]

2. Sands, W.; McNeal, J.; Ochi, M.; Urbanek, T.; Jemni, M.; Stone, M. Comparison of the Wingate and Bosco Protocol. J. Strength Cond. Res. 2004, 18, 810-815.

3. Rodriguez-Rosell, D.; Mora-Custodio, R.; Franco-Marquez, F.; Yaez-Garcia, J.; Gonzalez-Badillo, J. Traditional vs. Sport-Specific Vertical Jump Tests: Reliability, Validity, and Relationship with the Legs Strength and Sprint Performance in Adult and Teen Soccer and Basketball Players. J. Strength Cond. Res. 2016, 31, 196-206. [CrossRef]

4. Barker, L.; Harry, J.; Mercer, J. Relationships Between Countermovement Jump Ground Reaction Forces and Jump Height, Reactive Strength Index, and Jump Time. J. Strength Cond. Res. 2015, 32, 248-254. [CrossRef]

5. Cooper, C.N.; Dabbs, N.C.; Davis, J.; Sauls, N.M. Effects of Lower-Body Muscular Fatigue on Vertical Jump and Balance Performance. J. Strength Cond. Res. 2020, 34, 2903-2910. [CrossRef] [PubMed]

6. Gribble, P.A.; Hertel, J. Effect of Lower-Extremity Muscle Fatigue on Postural Control. Arch. Phys. Med. Rehabiliation 2004, 85, 589-592. [CrossRef] [PubMed]

7. Venckunas, T.; Krusnauskas, R.; Snieckus, A.; Eimantas, N.; Baranauskiene, N.; Skurvydas, A.; Brazaitis, M.; Kamandulis, S. Acute Effects of Very Low-Volume High-Intensity Interval Training on Muscular Fatigue and Serum Testosterone Level Vary According to Age and Training Status. Eur. J. Appl. Physiol. 2019, 119, 1725-1733. [CrossRef] [PubMed]

8. Dennison, K.J.; Mullineaux, D.R.; Yates, J.W.; Abel, M.G. The Effect of Fatigue and Training Status on Firefighter Performance. J. Strength Cond. Res. 2012, 26, 1101-1109. [CrossRef] [PubMed]

9. Lima, C.D.; Brown, L.E.; Wong, M.A.; Leyva, W.D.; Pinto, R.S.; Cadore, E.L.; Ruas, C.V. Acute Effects of Static vs. Ballistic Stretching on Strength and Muscular Fatigue Between Ballet Dancers and Resistance-Trained Women. J. Strength Cond. Res. 2016, 30, 3220-3227. [CrossRef]

10. Edge, J.; Mündel, T.; Weir, K.; Cochrane, D.J. The Effects of Acute Whole Body Vibration as a Recovery Modality Following High-Intensity Interval Training in Well-Trained, Middle-Aged Runners. Eur. J. Appl. Physiol. 2009, 105, 421-428. [CrossRef]

11. Dabbs, N.C.; Brown, L.; Garner, J.C. Effects of Whole Body Vibration on Vertical Jump Performance Following Exercise Induced Muscle Damage. Int. J. Kinesiol. Sports Sci. 2014, 2, 24-30. [CrossRef]

12. Weber, M.D.; Servedio, F.J.; Woodall, W.R. The Effects of Three Modalities on Delayed Onset Muscle Soreness. J. Orthop. Sports Phys. 1994, 20, 236-242. [CrossRef]

13. Webb, N.P.; Harris, N.K.; Cronin, J.B.; Walker, C. The Relative Efficacy of Three Recovery Modalities After Professional Rugby League Matches. J. Strength Cond. Res. 2013, 27, 2449-2455. [CrossRef]

14. Adams, J.B.; Edwards, D.; Serviette, D.; Bedient, A.M.; Huntsman, E.; Jacobs, K.A.; Del Rossi, G.; Roos, B.A.; Signorile, J.F. Optimal Frequency, Displacement, Duration, and Recovery Patterns to Maximize Power Output Following Acute Whole-Body Vibration. J. Strength Cond. Res. 2009, 23, 237-245. [CrossRef] [PubMed]

15. Jordan, M.J.; Norris, S.R.; Smith, D.J.; Herzog, W. Vibration Training: An Overview of the Area, Training Consequences, and Future Considerations. J. Strength Cond. Res. 2005, 19, 459-466. [CrossRef]

16. Wilcock, I.M.; Whatman, C.; Harris, N.; Keogh, J.W.L. Vibration Training: Could It Enhance the Strength, Power, or Speed of Athletes? J. Strength Cond. Res. 2009, 23, 593-603. [CrossRef] [PubMed]

17. Martin, B.J.; Park, H.S. Analysis of the Tonic Vibration Reflex: Influence of Vibration Variables on Motor Unit Synchronization and Fatigue. Eur. J. Appl. Physiol. Occup. Physiol. 1997, 75, 504-511. [CrossRef] [PubMed]

18. Park, H.S.; Martin, B.J. Contribution of the Tonic Vibration Reflex to Muscle Stress and Muscle Fatigue. Scand. J. Work Environ. Health 1993, 19, 35-42. [CrossRef] [PubMed]

19. Dabbs, N.C.; Lundahl, J.A.; Garner, J.C. Effectiveness of Different Rest Intervals Following Whole-Body Vibration on Vertical Jump Performance Between College Athletes and Recreationally Trained Females. Sports 2015, 3, 258-268. [CrossRef] 
20. Torvinen, S.; Kannu, P.; Sievänen, H.; Järvinen, T.A.H.; Pasanen, M.; Kontulainen, S.; Järvinen, T.L.N.; Järvinen, M.; Oja, P.; Vuori, I. Effect of a Vibration Exposure on Muscular Performance and Body Balance. Randomized Cross-over Study. Clin. Physiol. Funct. Imaging 2002, 22, 145-152. [CrossRef]

21. Pojskic, H.; Pagaduan, J.; Uzicanin, E.; Babajic, F.; Muratovic, M.; Tomljanovic, M. Acute Effects of Loaded Whole Body Vibration Training on Performance. Asian J. Sports Med. 2015, 6, e24054. [CrossRef]

22. Cormie, P.; Deane, R.S.; Triplett, N.T.; McBride, J.M. Acute Effects of Whole-Body Vibration on Muscle Activity, Strength, and Power. J. Strength Cond. Res. 2006, 20, 257-261. [CrossRef]

23. Dabbs, N.C.; Muñoz, C.X.; Tran, T.T.; Brown, L.E.; Bottaro, M. Effect of Different Rest Intervals After Whole-Body Vibration on Vertical Jump Performance. J. Strength Cond. Res. 2011, 25, 662-667. [CrossRef]

24. Bosco, C.; Colli, R.; Introini, E.; Cardinale, M.; Tsarpela, O.; Madella, A.; Tihanyi, J.; Viru, A. Adaptive Responses of Human Skeletal Muscle to Vibration Exposure. Clin. Physiol. 1999, 19, 183-187. [CrossRef]

25. McBride, J.M.; Nuzzo, J.L.; Dayne, A.M.; Israetel, M.A.; Nieman, D.C.; Triplett, N.T. Effect of an Acute Bout of Whole Body Vibration Exercise on Muscle Force Output and Motor Neuron Excitability. J. Strength Cond. Res. 2009, 24, 184-189. [CrossRef] [PubMed]

26. Ronnestad, B.R. Acute Effects of Various Whole-Body Vibration Frequencies on Lower-Body Power in Trained and Untrained Subjects. J. Strength Cond. Res. 2009, 23, 1309-1315. [CrossRef]

27. Eklund, G.; Hagbarth, K.E. Normal Variability of Tonic Vibration Reflexes in Man. Exp. Neurol. 1966, 16, 80-92. [CrossRef]

28. Desmedt, J.E.; Godaux, E. Mechanism of the Vibration Paradox: Excitatory and Inhibitory Effects of Tendon Vibration on Single Soleus Muscle Motor Units in Man. J. Physiol. 1978, 285, 197-207. [CrossRef] [PubMed]

29. Taber, C.; Bellon, C.; Abbott, H.; Bingham, G. Roles of Maximal Strength and Rate of Force Development in Maximizing Muscular Power. J. Strength Cond. Res. 2016, 38, 71-78. [CrossRef]

30. Young, W.B. Transfer of Strength and Power Training to Sports Performance. Int. J. Sports Physiol. Perform. 2006, 1, 74-83. [CrossRef]

31. Cormie, P.; McCaulley, G.O.; McBride, J.M. Power versus Strength-Power Jump Squat Training: Influence on the Load-Power Relationship. Med. Sci. Sports Exerc. 2007, 39, 996-1003. [CrossRef]

32. Haff, G.G.; Carlock, J.M.; Hartman, M.J.; Kilgore, J.L.; Kawamori, N.; Jackson, J.R.; Morris, R.T.; Sands, W.A.; Stone, M.H. Force-Time Curve Characteristics of Dynamic and Isometric Muscle Actions of Elite Women Olympic Weightlifters. J. Strength Cond. Res. 2005, 19, 741-748. [CrossRef] [PubMed]

33. Beckham, G.K.; Lamont, H.S.; Sato, K.; Ramsey, M.W.; Stone, M.H. Isometric Strength of Powerlifters in Key Positions of the Conventional Deadlift. J. Trainology 2012, 1, 32-35. [CrossRef]

34. Beckham, G.; Mizuguchi, S.; Carter, C.; Sato, K.; Ramsey, M.; Lamont, H.; Hornsby, G.; Haff, G.; Stone, M. Relationships of Isometric Mid-Thigh Pull Variables to Weightlifting Performance. J. Sports Med. Phys. Fit. 2013, 53, 573-581.

35. Slawinski, J.; Bonnefoy, A.; Levêque, J.-M.; Ontanon, G.; Riquet, A.; Dumas, R.; Chèze, L. Kinematic and Kinetic Comparisons of Elite and Well-Trained Sprinters during Sprint Start. J. Strength Cond. Res. 2010, 24, 896-905. [CrossRef] [PubMed]

36. Cazás-Moreno, V.L.; Gdovin, J.R.; Williams, C.C.; Allen, C.R.; Fu, Y.-C.; Brown, L.E.; Iii, J.C.G. Influence of Whole Body Vibration and Specific Warm-Ups on Force during an Isometric Mid-Thigh Pull. Int. J. Kinesiol. Sports Sci. 2015, 3, 31-39.

37. Hornsby, W.G.; South, M.A.; Stone, J.D.; Lamont, H.S.; Haff, G.G.; Stone, M.H. The Acute Effects of Whole Body Vibration on Isometric Mid-Thigh Pull Performance. Vibration 2020, 3, 85-98. [CrossRef]

38. Merrigan, J.J.; Dabbs, N.C.; Jones, M.T. Isometric Mid-Thigh Pull Kinetics: Sex Differences and Response to Whole-Body Vibration. J. Strength Cond. Res. 2020, 34, 2407-2411. [CrossRef]

39. Comfort, P.; Sweart, A.; Bloom, L.; Clarkson, B. Relationships Between Strength, Sprint, and Jump Performance in Well-Trained Youth Soccer Players. J. Strength Cond. Res. 2017, 28, 173-177. [CrossRef]

40. Cronin, J.; Hansen, K. Strength and Power Predictors of Sports Speed. J. Strength Cond. Res. 2005, 19, 349-357. [PubMed]

41. Nuzzo, J.L.; McBride, J.M.; Cormie, P.; McCaulley, G.O. Relationship between Countermovement Jump Performance and Multijoint Isometric and Dynamic Tests of Strength. J. Strength Cond. Res. 2008, 22, 699-707. [CrossRef]

42. Bosco, C.; Luhtanen, P.; Komi, P. A Simple Method for Measurement of Mechanical Power in Jumping. Eur. J. Appl. Physiol. 1983, 50, 273-301. [CrossRef] [PubMed]

43. Benjaminse, A.; Habu, A.; Sell, T.; Abt, J.; Fu, F.; Myers, J.; Lephart, S. Fatigue Alters Lower Extremity Kinematics During A Single-Leg Stop-Jump Task. Knee Surg. Sports Traumatol. Arthrosc. 2008, 16, 400-407. [CrossRef] [PubMed]

44. Smilios, I. Effects of Varying Levels of Muscular Fatigue on Vertical Jump Performance. J. Strength Cond. Res. 1998, 12, 204-208.

45. Wong, T.L.; Huang, C.F.; Chen, P.C. Effects of Lower Extremity Muscle Fatigue on Knee Loading During a Forward Drop Jump to a Vertical Jump in Female Athletes. J. Hum. Kinet 2020, 72, 5-13. [CrossRef] [PubMed]

46. Colson, S.S.; Petit, P.-D.; Hébreard, L.; Tessaro, J.; Pensini, M. Whole Body Vibration Does Not Enhance Muscle Activation. Int. J. Sports Med. 2009, 30, 841-844. [CrossRef]

47. Jordan, M.; Norris, S.; Smith, D.; Herzog, W. Acute Effects of Whole-Body Vibration on Peak Isometric Torque, Muscle Twitch Torque and Voluntary Muscle Activation of the Knee Extensors. Scand. J. Med. Sci. Sports 2010, 20, 535-540. [CrossRef]

48. Bullock, N.; Martin, D.T.; Ross, A.; Rosemond, C.D.; Jordan, M.J.; Marino, F.E. Acute Effect of Whole-Body Vibration on Sprint and Jumping Performance in Elite Skeleton Athletes. J. Strength Cond. Res. 2008, 22, 1371-1374. [CrossRef] 
49. Cochrane, D.; Stannard, S. Acute Whole Body Vibration Training Increases Vertical Jump and Flexibility Performance in Elite Female Field Hockey Players. Br. J. Sports Med. 2005, 39, 860-865. [CrossRef]

50. Yang, W.-W.; Chou, L.-W.; Chen, W.-H.; Shiang, T.-Y.; Liu, C. Dual-Frequency Whole Body Vibration Enhances Vertical Jumping and Change-of-Direction Ability in Rugby Players. J. Sport Health Sci. 2017, 6, 346-351. [CrossRef] 